\title{
EXPERIMENTAL INVESTIGATION AND FAULT DIAGNOSIS THROUGH CBM TECHNIQUES FOR ANTIFRICTION BEARING OF
}

\author{
MILL FAN \\ DEVARABHOTLA SAI CHANDRA ${ }^{1}$, Y. SEETHARAMA RAO ${ }^{2} \&$ M. SAMBAIAH $^{3}$ \\ ${ }^{I}$ PG Student, Department of Mechanical Engineering, G.V.P College of Engineering (Autonomous), \\ Madhurawada, Visakhapatnam, Andhra Pradesh, India \\ ${ }^{2}$ Associate Professor, Department of Mechanical engineering, G.V.P College of Engineering (Autonomous), \\ Madhurawada, Visakhapatnam, Andhra Pradesh, India \\ ${ }^{3}$ Manager, Department of Technical Services, RashtriyaIspat Nigam Limited Steel Plant, Visakhapatnam, India
}

\begin{abstract}
This project is concentrated on fault diagnosis in anti-friction bearings, at an early stage, to stop the catastrophic failure of Mill fan motor, and to find the root cause of failure component. It utilizes correlation of vibration data i.e. Overall amplitude, FFT spectrums and time waveform signals. It helps in not only finding bearing faults, but also to identify the root cause for its deterioration. Experiments are carried out by taking overall vibration readings in no-load condition on Drive and Non-Drive Ends of motor bearing housings in the tri-axial direction using the accelerometer. Based on readings, it is observed that dominating vibration amplitude observed at Motor Drive End bearing in vertical and axial directions only, the pattern directing towards the localized problem do not influence the other bearing in the equipment. In the FFT spectrums of motor bearing, dominating peaks appeared at 3960cpm, which is matching Harmonic Frequencies of rotating RPM of the motor. The above observations, conditions and predominant frequencies appeared in the spectrums, directing towards suspicion of bearing condition.
\end{abstract}

KEYWORDS: Vibration Spectrum Analysis, CBM Techniques, Bearing Elements Defects, Rolling Element Bearing \& Fault Identification

Received: Jul 03, 2018; Accepted: Jul 24, 2018; Published: Jul 31, 2018; Paper Id.: IJMPERDAUG201886

\section{INTRODUCTION}

In industrial context, Condition Based Maintenance is one of the techniques to presuppose knowledge of machine's condition and its rate of change, which can be ascertained by choosing an appropriate parameter for measuring deterioration and recording its value at regular intervals - either on a routine or continuous basis. Mostly, it is required to be done while the machine is in running condition. The data obtained may then be analyzed to give a warning of failure. This activity is called Condition Monitoring, and its essential component parts are data collection, recording and their interpretation. An organized data collection and collation system is very essential part of this program, in addition to the decision regarding parameters to be measured on machines in industries. Condition Monitoring is essentially a measurement of the fault trend of a component. Knowledge of various types of faults will be helpful in understanding the scope of condition monitoring. The observable type of regular failures lends themselves to inspection. The Condition Based Maintenance using condition monitoring techniques is 
eminently suitable for these types of failures.

P. K kankar et al. [1] Conducted fault diagnosis of rolling element bearings, which is outperformed by the use of signal processing methods. It unveils the various physical modulation mechanisms present in vibration response of rolling element bearings. Feature recognition system is presented in this paper for detection of bearing faults, by classifying those using soft computing techniques, like ANN, SVM and SOM. The performance of SVM is found to be best due to its inherent generalization capability. M. L. D Wong et al. [2] showed vibration signals of roller element bearings are acquired in the time domain and resample with a random Bernoulli matrix to emulate the compressed sensing mechanism. Demonstrated that it is possible to sample the vibration data of roller element bearings at less than the NY Quist rate and reconstruct the signal for fault classification. Rummaan Bin Amir et al. [3] validated experiment on roller bearing using Support vector method (SVM). The Vibration signal is followed by feature extraction in time and frequency domain and on this basis, fault classification is performed. The vibration signature, in case of rotating machines for fault detection among numerous computationally intelligent classification algorithms. Through the results and simulations produced, efficient fault detection can not only be done using classical SVM, but even better results are obtained using one class SVM. Ma Li and Zhang Tao [4] investigated rolling element bearing using SVM techniques and SVM classifier, used for initial classification. Basic probabiltiy assignment (BPA) was by SVM classification results. The experimental results show that, this method can effectively identify Rolling health status, which has high recognition accuracy, stability, and broad applicability. H. Saruhanet al. [5] performed experiments in four different speeds with two load intervals on bearings. The vibration data captured and validation is composed of four different defects states of rolling element bearing (REB) - outer race defect, inner raceway defects, ball defect and the combination of the bearing elements defect-and one representing the normal state. K. Yavanarani et al. [6] has done experiments on engine test bed, in order to verify that it meets the particular at various load accumulation. These are often carried with troubleshooting, in order to determine whether vibration levels are within acceptable limits at given speed. Khadim Moin Siddiqui et al.[7] analyzed bearing fault on squirrel Cage, Induction motor has been diagnosed in the transient condition as well as steady-state condition by signal processing techniques, like FFT by time domain as well as wavelet transform fir early fault detection. B. S Kim et al.[8] conducted an experiment on grinding spindle-typed rotor-bearing system and carried out tests to identify system characteristics and operating range, used FFT, Short-Time Fourier Transformation (STFT); Winger-Ville Distribution (WVD) was applied in varying speeds for vibration data of normal and shaft -cracked rotor. Faris Elasha et al. [9] studied Acoustics Emission (AE) technology for diagnosis approach for detecting faults in bearing faults in helicopter gearbox and detected a fault in bearing, and proved that $\mathrm{AE}$ diagnosis has the ability to diagnose helicopter gearbox. Abdullah et al. [10] discussed experiment on bearing using Acoustic Emission (AE) and vibration analysis over a range of speed and load sv, and compared these two data to investigate fault detection.

The current work focuses on real-time monitoring of motor health condition, and to find the failure bearing component in running condition using FFT analyzer. The main objective of this work is to find the root cause that leads to bearing deterioration, and eliminating those forces by mapping of vibration amplitude on motor bearing with the trend, over a period of time frame, which indicates the condition of the bearing. Comparing the data of motor after corrective action and replacing with new bearing with existing motor readings. 


\section{EXPERIMENTAL INVESTIGATION OF MILL FAN MOTOR}

Using Vibxpert 2011 FFT analyzer to track and record readings taken by placing accelerometer on Motor Drive End (MDE) and Non-Drive End (NDE) bearing housing and vibration, overall amplitude values are taken in $\mathrm{mm} / \mathrm{s}$ in the tri-axial direction of the housing. These readings are taken in Full Load condition, and found amplitude readings in axial and vertical directions are dominating. Later, this collected data is fed into a computer by using Omni trend software, where, information is transferred and helpful in knowing the past data also by trends, which helps in analyzing the problem by checking that the reading are within acceptable limits or not. The nature of the problem in machinery is identified by its unique vibration characteristics. By analyzing vibration amplitude pattern, directing towards a localized problem, not influencing the other bearings in the equipment. The cause of failure identified by detailed checking causes of bearing faults like misalignment, Mechanical looseness etc., by eliminating one by one, that causes bearing failure.

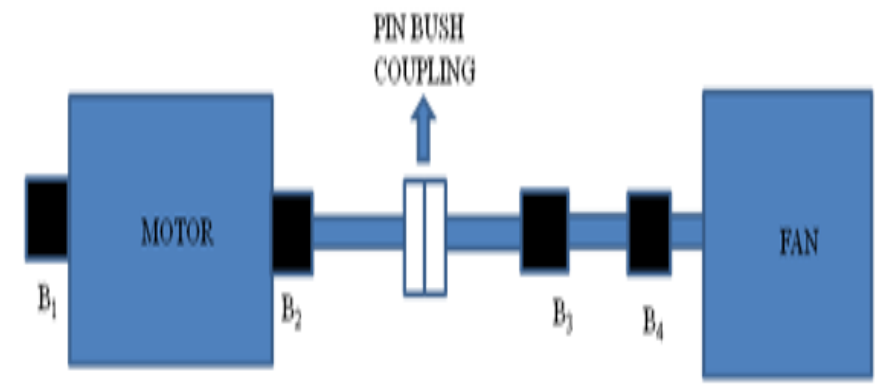

Figure 1: Measuring Point Layout for Mill Fan Motor

Where, B1- Motor Non-Drive End (MNDE)

B2-Motor Drive End (MDE)

B3-Fan Drive End (FDE)

B4-Fan Non-Drive End (FNDE)

Table 1: Equipment Details for Mill Fan

\begin{tabular}{|l|l|}
\hline Equipment Type & \multicolumn{1}{|c|}{ Single Suction Over Hung Rotor Fan } \\
\hline Location & CDCP/Coke Oven \\
\hline Pressure & $800 \mathrm{MM} \mathrm{WC}$ \\
\hline Impeller diameter & 2600MM \\
\hline Motor Type & 3-Phase Induction Motor \\
\hline Rating & $630 \mathrm{Kw}$ \\
\hline Operating Voltage & $6600 \mathrm{~V}$ \\
\hline Full Load Current & $69 \mathrm{Amp}$ \\
\hline Motor Speed & $1000 \mathrm{RPM}$ \\
\hline Handling Medium & Nitrogen \\
\hline Coupling Type & Pin Bush \\
\hline Foundation Type & Concrete \\
\hline Motor Bearing & Double Row Spherical Roller Bearing (22230) \\
\hline
\end{tabular}

As per ISO 2372, this equipment belongs to class-3, and the maximum vibration limits for this equipment is 4.5 $\mathrm{mm} / \mathrm{observed}$ vibration, readings should not exceed this value. 


\section{Analytical Calculation Formulas for Bearing Fault Frequencies}

Bearing fault frequencies calculation as per formula [9]

$\mathrm{BPFO}=\frac{\mathrm{N}_{\mathrm{b}}}{2} \mathrm{XS}\left(1-\frac{\mathrm{B}_{\mathrm{d}}}{\mathrm{P}_{\mathrm{d}}} \operatorname{COS}(\phi)\right)$

$\mathrm{BPFI}=\frac{\mathrm{N}_{\mathrm{b}}}{2} \times \mathrm{S}\left(1+\frac{\mathrm{B}_{\mathrm{d}}}{\mathrm{P}_{\mathrm{d}}} \operatorname{COS}(\phi)\right)$

Speed S - Revolutions per Minute - 996

$\mathrm{B}_{\mathrm{d}}$ - Ball or roller diameter-28.72 mm

$\mathrm{N}_{\mathrm{b}}$ - Number of balls or rollers - 18

$P_{d}$ - Pitch diameter - $217.39 \mathrm{~mm}$

$\phi$ - Contact angle - 9.5 degrees

BPFI - Ball Pass Frequency of Inner ring

BPFO - Ball Pass Frequency of outer race

\section{Physical Fault Detection of Bearing after Dismantling}

From above and below, a knurling pattern is observed on one side due to slip of rolling elements on outer race, and normal wear is observed on another side of bearing in Drive End (DE) due to bearing fault on the outer race. In NonDrive End (NDE), normal wear is seen on both sides of the outer race.

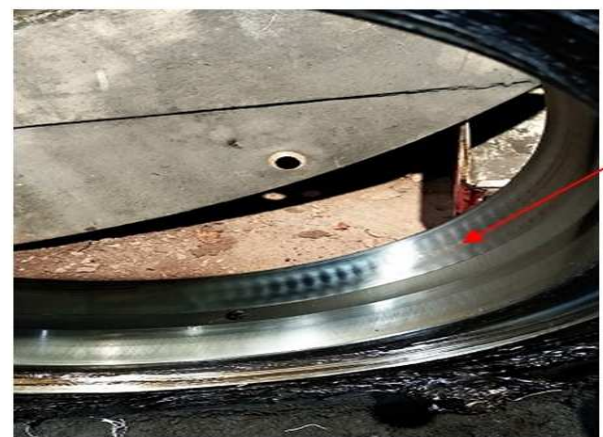

Knurling pattern

defect due to

deterioration

Figure 2: Knurling Pattern are Observed on Motor Drive End (MDE) Bearing

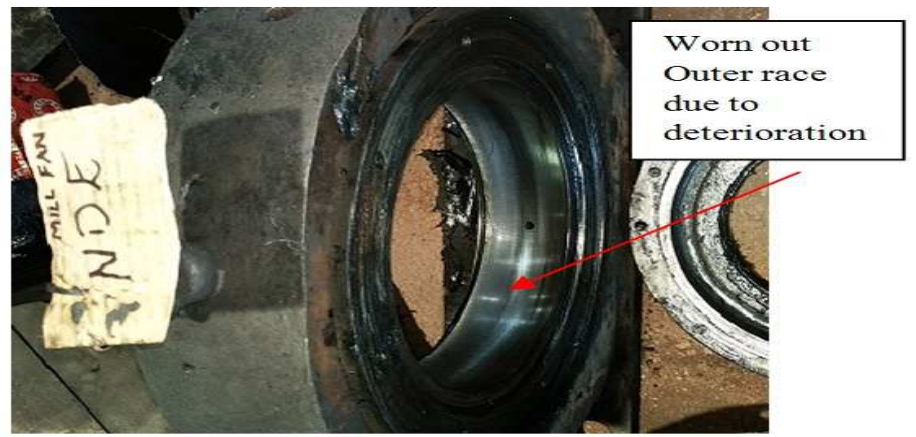

Figure 3: Normal Wear Observed on Motor Non- Drive End (NDE) Bearing 


\section{RESULTS AND DISCUSSIONS}

Overall vibration readings are helpful in analyzing the motor health condition. The exact fault detection can be analyzed on which direction dominating peak vales appeared, based on that, we can identify the exact fault that leads to bearing deterioration of the values taken in mm/s. Amplitude range before replacement of new bearing for Motor Drive End, and Non-Drive End readings are tabulated in table 2 and amplitude range, after replacement of bearings in Motor Drive and Non-Drive Ends readings are tabulated in table 3.

\section{Table 2: Overall Vibration Data in No Load Condition in $\mathbf{m m} / \mathbf{s}$ before Replacement of Bearings for Motor}

\begin{tabular}{|l|c|c|}
\hline \multicolumn{1}{|c|}{ Axis } & MNDE & MDE \\
\hline Vertical & 2.82 & 3.05 \\
\hline Horizontal & 1.71 & 2.72 \\
\hline Axial & 3.63 & 5.49 \\
\hline
\end{tabular}

Table 3: Overall Vibration Reading after Replacing with New Bearing for Motor

\begin{tabular}{|l|c|c|}
\hline Direction & MNDE & MDE \\
\hline Vertical & 0.57 & 1.5 \\
\hline Horizontal & 0.51 & 1.15 \\
\hline Axial & 0.91 & 1.11 \\
\hline
\end{tabular}

From above table 2, it is observed that dominating peaks are high on Vertical and Axial direction on Motor Drive End side. The readings were greatly reduced in table 3, after replacement of motor bearing, it is a sign that motor is in healthy condition.

MDE Vertical Direction Spectrum before Replacement of Bearing

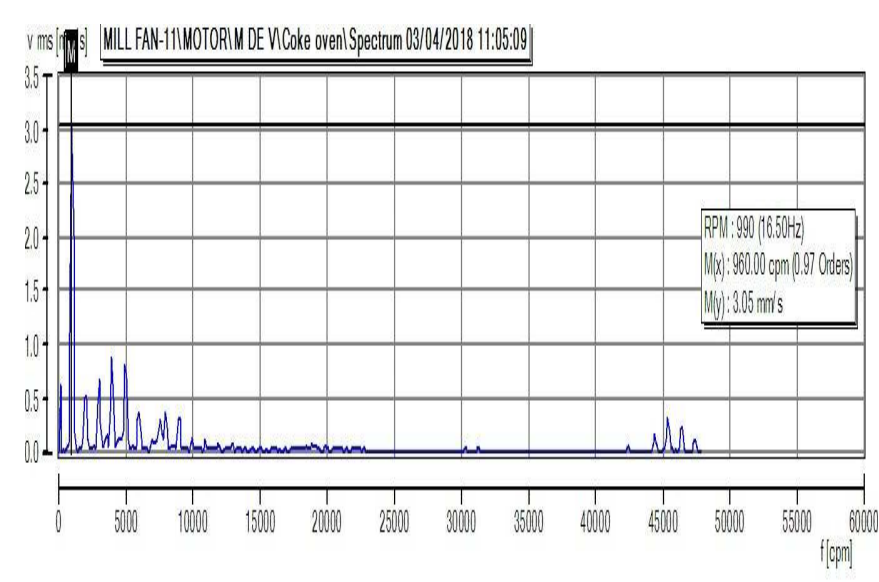

Figure 4: MDE Vertical Spectrum Ranging Amplitude 3.05 mm/s at 960 CPM 
MDE Axial Direction Spectrum before Replacement of Bearing

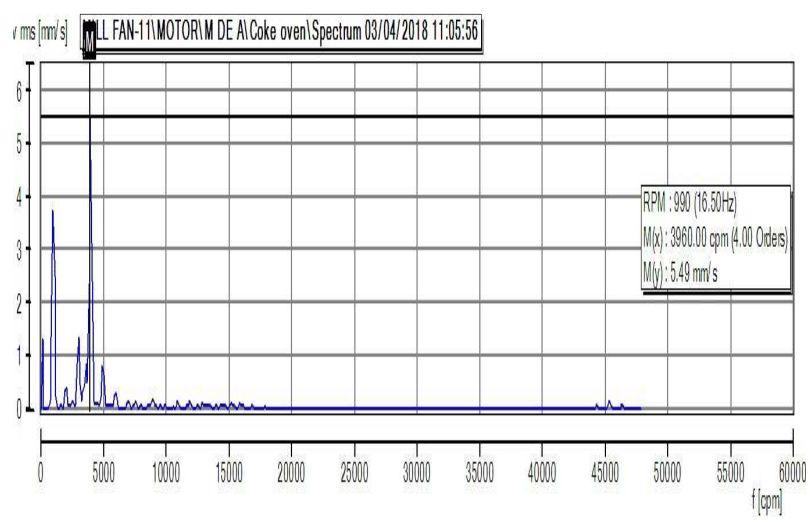

Figure 5: MDE Axial Spectrum Ranging Amplitude $5.49 \mathrm{~mm} / \mathrm{s}$ at $3960 \mathrm{CPM}$

MDE Vertical Direction Spectrum after Replacement of Bearing

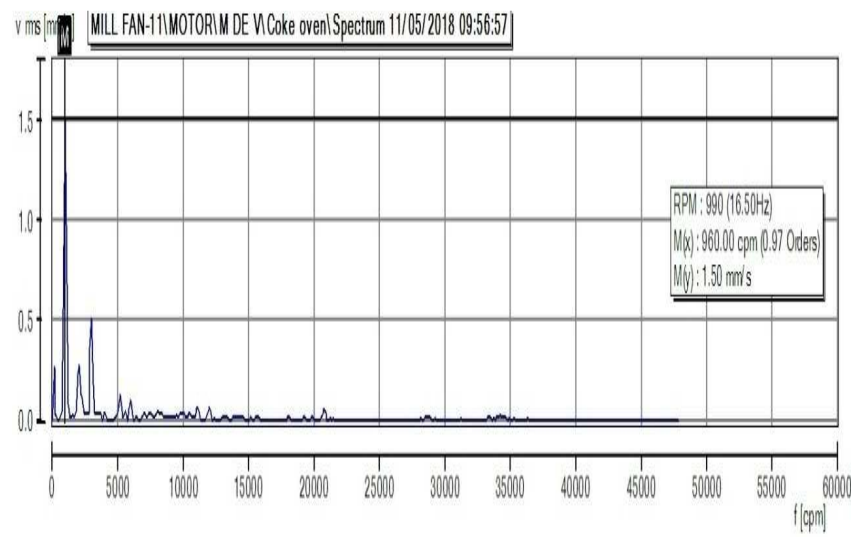

Figure 6: MDE Vertical Spectrum Ranging Amplitude $1.50 \mathrm{~mm} / \mathrm{s}$ at $960 \mathrm{cpm}$

MDE Axial Direction Spectrum after Replacement of Bearing

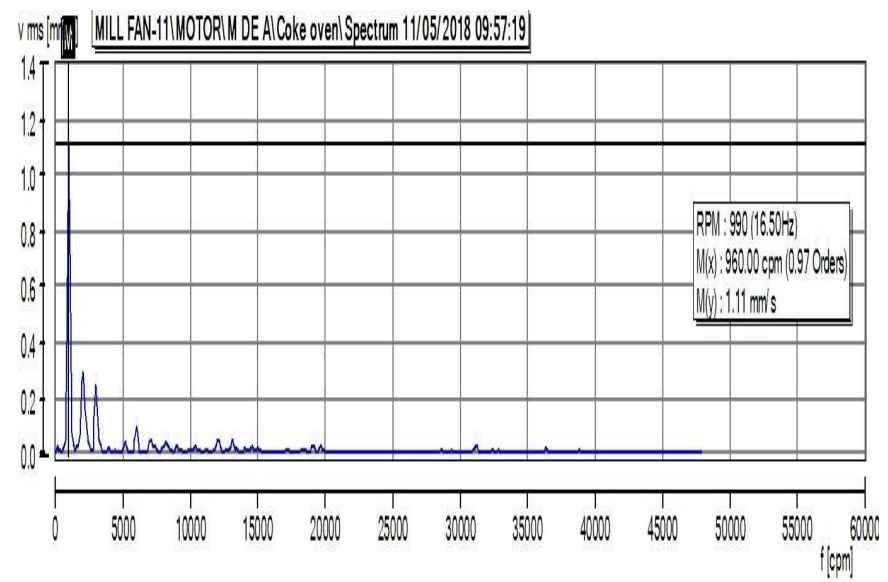

Figure 7: MDE Axial Spectrum Ranging Amplitude $1.11 \mathrm{~mm} / \mathrm{s}$ at $960 \mathrm{cpm}$ 
From above spectrums, it is observed that from Fig 5 Maximum amplitude $5.49 \mathrm{~mm} / \mathrm{s}$ appeared at the axial direction and predominant frequencies appeared at $3974 \mathrm{cpm} \mathrm{(4x),} \mathrm{which} \mathrm{is} \mathrm{close} \mathrm{to} \mathrm{Harmonic} \mathrm{frequencies} \mathrm{of} \mathrm{the} \mathrm{motor.}$ After replacement of motor bearing, it is amplitude which is greatly reduced to $1.11 \mathrm{~mm} / \mathrm{s}$ appeared at $960 \mathrm{cpm}$, which is harmonic frequencies of the motor.

$$
\begin{aligned}
\mathrm{BPFI} & =\frac{\mathrm{N}_{\mathrm{b}}}{2} \mathrm{X} \mathrm{S}\left(1+\frac{\mathrm{B}_{\mathrm{d}}}{\mathrm{P}_{\mathrm{d}}} \operatorname{COS}(\phi)\right)=\frac{18}{2} \times 996\left(1+\frac{28.72}{217.39} \operatorname{COS}(9.5)\right) \\
& =\frac{10132.017}{2}=5066 \mathrm{cpm} \\
\mathrm{BPFO} & =\frac{\mathrm{N}_{\mathrm{b}}}{2} X \mathrm{~S}\left(1-\frac{\mathrm{B}_{\mathrm{d}}}{\mathrm{P}_{\mathrm{d}}} \operatorname{COS}(\phi)\right)=\frac{18}{2} \times 996\left(1-\frac{28.72}{217.39} \operatorname{COS}(9.5)\right) \\
& =7795.98 \mathrm{cpm} \\
& =\frac{7795.98}{2}=3897.99 \mathrm{cpm}
\end{aligned}
$$

From the calculations, it is obtained that predominant frequency in the spectrums ie $3974 \mathrm{cpm}$, which is very close to the subharmonic of ball pass frequency of the outer race(BPFO) of the bearing 22230.

comparision graph before and After repalcement of bearing in vertical direction on Motor Drive End Side

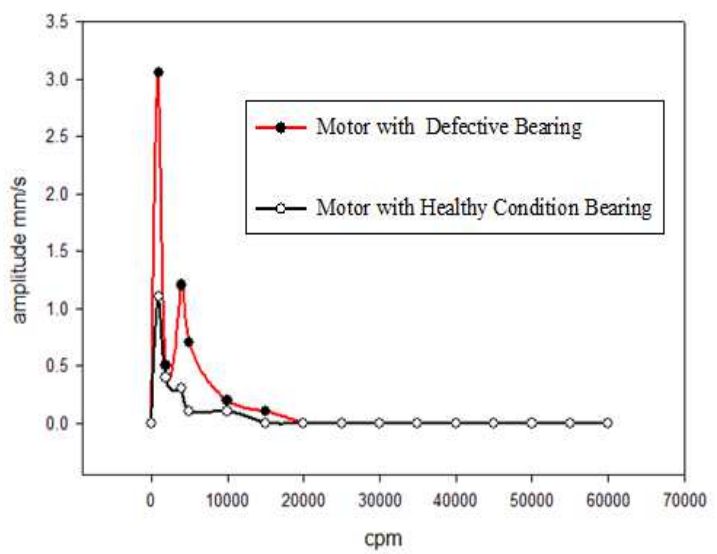

Figure 8: Reduction in Amplitude on MDE Vertical Direction

Comparision Graph Before and After repalcing of bearings in Axial Direction on Motor Drive End side

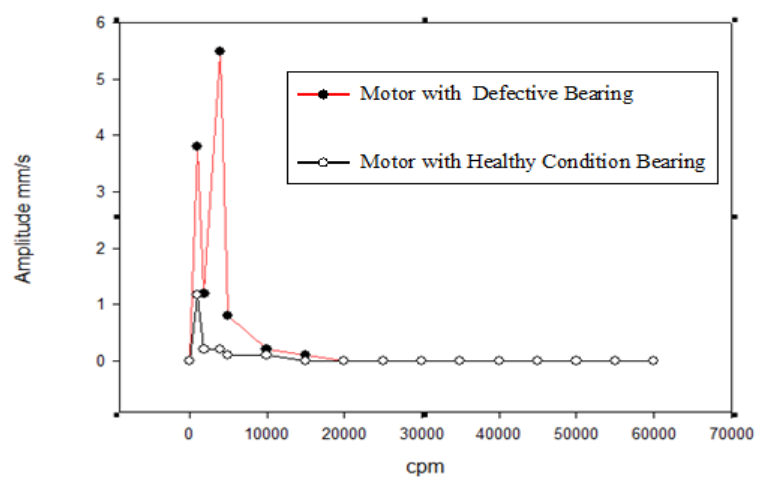

Figure 9: Reduction in Amplitude on MDE Axial Direction 


\section{CONCLUSIONS}

Premature failure of the bearing will happen, only if any manufacturing defects are developed during the process of manufacturing. After placing in the operation of any bearing, it may fail due to Normal Aging Effects. Early failure of bearing, after taking into operation is not the problem of bearing, but some external forces are responsible for their failure

- As per calculated equations, the predominant frequency in the spectrums i.e $3960 \mathrm{cpm}$, which is very close to the sub harmonic of ball pass frequency of the outer race(BPFO) of the bearing 22230.

- Fault diagnosis is done by elimination process, which causes bearing failure, to find the root causes that actually lead to deterioration of bearing.

- Proper seating of Bearing on the shaft in the housing was done, and shaft to shaft misalignment with laser kit has been done, and attained zero to zero accuracy was achieved.

- The vibration Amplitudes were greatly reduced from $5.49 \mathrm{~mm} / \mathrm{s}$ to $1.11 \mathrm{~mm} / \mathrm{s}$ in the axial direction of the motor drive end bearing, after replacing with a new bearing.

- Overall vibration readings also reduced at remaining measuring points in the triaxial direction.

- Temperature readings also within the Limits on the shaft, it is 54 degrees and on the bearing housing, it is 58 degrees centigrade on Drive End Bearing.

\section{REFERENCES}

1. P. K. Kankar, Satish, Sharma, S.P.Harsha (2013)."Fault diagnosis of rolling element bearing using cyclic autocorrelation and wave lettransform", Neurocomputing, vol.110, pp.9-17.

2. M. L. D. Wong, M. Zhang, A. K. Nandi (2015). "Health Status Identification of Rolling Bearing Based on SVM and Improved Evidence Theory"23rd European Signal Processing Conference, pp.2256-2260.

3. Rummaan Bin Amir, Sufi Tabassum Gul and Abdul Qayyum Khan (2016)."A Comparative Analysis of Classical and One Class SVM Classifiers for Machine Fault Detection Using Vibration Signals", IEEE

4. Ma Li, Zhang Tao (2016)."Health Status Identification of Rolling Bearing Based on SVM and Improved Evidence Theory", pp.378-382, IEEE.

5. J. Rafiee, P. W. Tse, A. Harifi, M. H. Sadeghi (2009).“A novel technique for selecting mother wavelet function using an intelligent fault diagnosis system", Expert Syst. App, pp.4862-4875.

6. Deepa, S., \& Umarani, R. (2016). Steganalysis on images based on the classification of image feature sets using SVM classifier. International Journal of Computer Science and Engineering (IJCSE), 5(5), 15-24.

7. N. Saravanan, V. N. S. Kumar Siddabattuni, K. I. Ramachandran (2008). "A comparative study on the classification of features by SVM and PSVM extracted using Morlet Wavelet for fault diagnosis", Expert Syst. Appl, vol.35, pp. 1351-1366.

8. K. M. Siddiqui, K. Sahay and V. K. Giri (2014). "Modelling and Detection of Bearing Fault in PWM Inverter Fed Induction Motor Drives", manager's Journal on Electrical Engineering, Vol. 8, No.1, pp. 11-24,.

9. S. Nandi and H. A. Toliyat (1999).“Condition Monitoring and Fault Diagnosis of electrical Machine”, Vol. 1, pp.197-204, In Proc. IEEE IAS Annual Meeting. 
10. NTN Bearing frequencies ntnamericans.com

11. Adel Boudiaf, Abederrazek Djebala, Hocine Bendjma, Adel Balaska, Amine Dahane (2016)."A Summary of Vibration Analysis Techniques for Fault Detection and Diagnosis in Bearing", 8th International Conference on Modelling, identification and contro, Alglers 
